\title{
Multipotent Adult Progenitor Cells Prevent Macrophage-Mediated Axonal Dieback and Promote Regrowth after Spinal Cord Injury
}

\author{
Sarah A. Busch, ${ }^{1}$ Jason A. Hamilton, ${ }^{2}$ Kevin P. Horn, ${ }^{1}$ Fernando X. Cuascut, ${ }^{1}$ Rochelle Cutrone, ${ }^{2}$ Nicholas Lehman, ${ }^{2}$ \\ Robert J. Deans, ${ }^{2}$ Anthony E. Ting, ${ }^{2}$ Robert W. Mays, ${ }^{2}$ and Jerry Silver ${ }^{1}$ \\ ${ }^{1}$ Department of Neurosciences, Case Western Reserve University, Cleveland, Ohio 44106, and 2Department of Regenerative Medicine, Athersys, Inc., \\ Cleveland, Ohio 44115
}

\begin{abstract}
Macrophage-mediated axonal dieback presents an additional challenge to regenerating axons after spinal cord injury. Adult adherent stem cells are known to have immunomodulatory capabilities, but their potential to ameliorate this detrimental inflammation-related process has not been investigated. Using an in vitro model of axonal dieback as well as an adult rat dorsal column crush model of spinal cord injury, we found that multipotent adult progenitor cells (MAPCs) can affect both macrophages and dystrophic neurons simultaneously. MAPCs significantly decrease MMP-9 (matrix metalloproteinase-9) release from macrophages, effectively preventing induction of axonal dieback. MAPCs also induce a shift in macrophages from an M1, or "classically activated" proinflammatory state, to an M2, or "alternatively activated" antiinflammatory state. In addition to these effects on macrophages, MAPCs promote sensory neurite outgrowth, induce sprouting, and further enable axons to overcome the negative effects of macrophages as well as inhibitory proteoglycans in their environment by increasing their intrinsic growth capacity. Our results demonstrate that MAPCs have therapeutic benefits after spinal cord injury and provide specific evidence that adult stem cells exert positive immunomodulatory and neurotrophic influences.
\end{abstract}

\section{Introduction}

Minimal regeneration occurs spontaneously after injury to the CNS, and therefore, it is critical to identify strategies that can halt loss of function and/or promote recovery (Tator, 2006; Eftekharpour et al., 2008). Traumatic spinal cord injury initiates a complex series of events leading to secondary injury and formation of a glial scar (Silver and Miller, 2004). Previous work from our laboratory has shown that the infiltration of phagocytic ED1+ macrophages coincides with long-distance axonal retraction, or dieback, from the initial site of a spinal cord lesion, resulting in a disadvantageous starting position for regenerating axons (Horn et al., 2008). Injured axons that become dystrophic because of the presence of inhibitory proteoglycans in their environment are particularly susceptible to attack by macrophages. In addition to the relative permissiveness of the substrate on which the axon is growing, several factors can affect the outcome of macrophage attack, including enhancement of the intrinsic growth potential of the neuron and alteration of macrophage-secreted factors

Received July 9, 2010; revised 0ct. 12, 2010; accepted 0ct. 26, 2010.

This work was supported by National Institutes of Health-National Institute of Neurological Disorders and Stroke Grant NS25713 (J.S.), the Brumagin-Nelson Fund for Spinal Cord Injury Research, National Institutes of Health Training Grant T32 AG00271 (S.A.B.), the New York State Spinal Cord Injury Research Program, and Athersys, Inc. We extend our thanks to $\mathrm{H}$. Hu for technical assistance, M. Pendergast for assistance with imaging, A. Hawthorne for assistance with statistical analysis, and P. Popovich and J. Woda for helpful comments on this manuscript.

This work was supported in part by a sponsored research agreement between J.S. and Athersys, Inc. S.A.B, J.A.H., N.L., R.J.D., A.E.T., and R.W.M. are employees of Athersys, Inc.

Correspondence should be addressed to Dr. Jerry Silver, Department of Neurosciences, Case Western Reserve University, 2109 Adelbert Road, SOM E-658, Cleveland, OH 44106. E-mail: jxs10@cwru.edu.

DOI:10.1523/JNEUROSCI.3566-10.2011

Copyright $\odot 2011$ the authors $\quad 0270-6474 / 11 / 310944-10 \$ 15.00 / 0$
(Busch et al., 2009). In addition, we have shown that macrophagemediated axonal dieback can be prevented in vitro by specific inhibition of matrix metalloproteinase-9 (MMP-9). Additionally, endogenous stem-like NG2+ progenitor cells that normally populate the lesion center can stabilize axons undergoing axonal dieback because of their expression of growth-promoting extracellular matrix molecules but cannot prevent the initiation of dieback (Busch et al., 2010).

In the past decade, adult stem cells have been isolated from multiple tissues and characterized in many laboratories (Mays et al., 2007; Ting et al., 2008). There is substantial interest in developing adult-derived stem cells as therapeutic agents for the treatment of CNS injury and disease (Biernaskie et al., 2007; Bambakidis et al., 2008; Barnabé-Heider and Frisén, 2008). Adult-derived adherent stem cells demonstrate a number of favorable characteristics including genetic stability, extensive expansion capacity, and low immunogenicity profiles that support allogeneic utility (Gnecchi et al., 2008). Functional improvement after administration of adult-derived cells has been demonstrated in multiple preclinical models of injury or disease; however, many aspects of their mechanism of action remain poorly understood (Caplan and Dennis, 2006). Additional investigation of the specific mechanisms underlying the beneficial effects after treatment with adult stem cells will be important as cellular therapeutics enter clinical development.

Multipotent adult progenitor cells (MAPCs) are a well characterized population of adherent stem cells isolated from adult bone marrow and other adult tissues (Jiang et al., 2002a,b) that can positively modulate the immune system (Kovacsovics- 
Bankowski et al., 2009). MAPCs are one of several populations of stem cells isolated from the bone marrow compartment, such as mesenchymal stem cells (MSCs) and marrow-isolated adult multilineage inducible (MIAMI) cells (Mays et al., 2007). Both MAPCs and MSCs have been shown to have strong immunomodulatory properties, and MAPCs are capable of extensive expansion in culture (Jiang et al., 2002b). Because of our previous observations of the negative effects of macrophages after injury, we sought to determine whether MAPCs could affect immune cells responding to the initial insult to prevent axonal dieback and promote regeneration.

\section{Materials and Methods}

Dorsal rootganglion neuron preparation. Dorsal root ganglia (DRGs) were harvested as previously described (Tom et al., 2004). Briefly, DRGs were dissected out of adult female Sprague Dawley rats (Harlan). Both the central and peripheral roots were removed and ganglia incubated in a solution of collagenase II ( $200 \mathrm{U} / \mathrm{ml}$; Worthington) and dispase II (2.5 $\mathrm{U} / \mathrm{ml}$; Roche) in HBSS. The digested DRGs were rinsed and gently triturated in fresh calcium- and magnesium-free HBSS (HBSS-CMF) three times followed by low-speed centrifugation. The dissociated DRGs were then resuspended in Neurobasal A medium supplemented with B-27, Glutamax, and penicillin/streptomycin (all from Invitrogen) and counted. DRGs were plated on Delta-T dishes (Thermo Fisher Scientific) at a density of 3000 cells $/ \mathrm{ml}$ for a total of 6000 cells/dish.

Time-lapse dish preparation. Delta-T cell culture dishes (Thermo Fisher Scientific) were prepared as described previously (Horn et al., 2008). Briefly, a single hole was drilled through the upper half of each dish to create a port for the addition of cells to the cultures during time-lapse microscopy. Dishes were then rinsed with sterile water and coated with poly-L-lysine $(0.1 \mathrm{mg} / \mathrm{ml}$; Invitrogen $)$ overnight at room temperature. Dishes were then rinsed with sterile water and allowed to dry. Aggrecan gradient spots were created by pipetting $2.0 \mu$ l of aggrecan solution $(2.0 \mathrm{mg} / \mathrm{ml}$; Sigma-Aldrich; in HBSS-CMF; Invitrogen) onto the culture surface and allowed to dry. Six spots were placed per dish. After the aggrecan spots dried completely, the entire surface of the dish was bathed in laminin solution ( $10 \mu \mathrm{g} / \mathrm{ml}$; BTI; in HBSS-CMF) for $3 \mathrm{~h}$ at $37^{\circ} \mathrm{C}$. The laminin bath was then removed immediately before plating of cells.

Rat macrophage cultures. NR8383 cells (ATCC; CRL-2192), an adult Sprague Dawley alveolar macrophage cell line, were cultured as described in previously (Yin et al., 2003). Briefly, cells were cultured in uncoated tissue culture flasks (Corning) in F-12K medium (Invitrogen) supplemented with 15\% FBS (Sigma-Aldrich), Glutamax, Penn/Strep (Invitrogen), and sodium bicarbonate (Sigma-Aldrich), and fed two to three times per week. To prepare the cell line macrophages for time-lapse microscopy experiments, cells were harvested with trypsin/EDTA (Invitrogen), washed three times, and plated in uncoated tissue culture flasks at a density of $1.0 \times 10^{6} / \mathrm{ml}$ in serum-free F-12K. Before use in time-lapse experiments, the cultured cell line macrophages were harvested with EDTA and a cell scraper and resuspended in Neurobasal A with the addition of HEPES ( $50 \mu \mathrm{M}$; Sigma-Aldrich) at a density of $2.5 \times$ $10^{5} / 70 \mu \mathrm{l}$.

Astrocyte culture. Cortical astrocytes were collected by removing the cortices from postnatal day 1 rats, which were then finely minced and treated with $0.5 \%$ trypsin/EDTA (Sigma-Aldrich). Cells were seeded in DMEM/F12 medium supplemented with 10\% fetal bovine serum (FBS), $2 \mathrm{~mm}$ Glutamax, $100 \mathrm{U} / \mathrm{ml}$ penicillin, and $100 \mu \mathrm{g} / \mathrm{ml}$ streptomycin (all from Invitrogen) on T75 flasks coated with poly-L-lysine, and shaken after $4 \mathrm{~h}$ to remove nonadherent cells. Astrocytes were considered mature after they were maintained in culture for $35 \mathrm{~d}$.

MAPC cultures. Sprague Dawley green fluorescent protein (GFP) rat MAPCs were prepared as described previously (Van't Hof et al., 2007). Rat MAPCs were originally generated by Dr. Felipe Prosper at the University of Navarra (Pamplona, Spain) and subsequently transduced with a GFP retrovirus in the laboratory of Dr. Catherine Verfaillie at the University of Minnesota (Minneapolis, MN). Sprague Dawley rat GFP+ MAPCs were expanded, banked, and evaluated by Athersys, Inc. In brief, the parental rat MAPC lines were acquired from two to four male rat donors. Cells were grown in medium consisting of low-glucose DMEM (Invitrogen), $0.4 \times$ MCDB-201 medium (Sigma-Aldrich), $1 \times$ ITS liquid medium supplement (Sigma-Aldrich), $1 \mathrm{mg} / \mathrm{ml}$ linoleic acid-albumin (Sigma-Aldrich), $100 \mathrm{U} / \mathrm{ml}$ penicillin G sodium $/ 100 \mu \mathrm{g} / \mathrm{ml}$ streptomycin sulfate (Invitrogen), $100 \mu \mathrm{M}$ 2-P-L-ascorbic acid (Sigma-Aldrich), 100 $\mathrm{ng} / \mathrm{ml}$ EGF (epidermal growth factor) (Sigma-Aldrich), $100 \mathrm{ng} / \mathrm{ml}$ PDGF (R\&D Systems), 50 nм dexamethasone (Sigma-Aldrich), $1000 \mathrm{U} / \mathrm{ml}$ ESGRO (Millipore Bioscience Research Reagents), and 2\% fetal bovine serum (HyClone). Marrow cells were resuspended in growth medium, viable cells were subsequently plated in fibronectin-coated $(10 \mathrm{ng} / \mathrm{ml}$; Invitrogen) $150 \mathrm{~cm}^{2}$ tissue culture flasks (Corning), and after $24 \mathrm{~h}$ all nonadherent cells were removed. After $14 \mathrm{~d}$, all colonies were trypsinized, combined, and replated at $75 \%$ confluence. The cells were maintained in $15 \mathrm{ml}$ of medium/flask at $37^{\circ} \mathrm{C}$ and $5.0 \% \mathrm{CO}_{2}$ with passaging every 3-4 d using trypsin/EDTA (Invitrogen), when at 30-40\% confluence, and reseeded at $500-1000$ cells $/ \mathrm{cm}^{2}$. Flow cytometric analysis of surface-expressed antigens confirmed that MAPCs used in this study are a homogeneous cell population. They are positive for CD29, CD90, CD44, and MHC class I, and are negative for MHC class II, CD45, CD106, and the costimulatory molecules CD80 and CD86, indicating that these cells are not derived from the hematopoietic lineage.

MAPC-conditioned medium. Cells were cultured as described above, and conditioned medium was collected after $48 \mathrm{~h}$ in $50 \mathrm{ml}$ conical tubes (BD Biosciences). The conditioned medium was spun down at $400 \times g$ for $5 \mathrm{~min}$ at $4^{\circ} \mathrm{C}$, and the supernatant was transferred to a new $50 \mathrm{ml}$ conical tube. MAPC-conditioned medium (MAPC-CM) was obtained as described above and concentrated 50-fold with an Amicon Microcon Ultracel YM-3 3000 MWCO centrifugal filter (Millipore).

MAPC-conditioned medium-treated macrophages. NR8383 rat macrophages were cultured as described above. One day before time-lapse microscopy experiments, macrophages were harvested with trypsin/ EDTA (Invitrogen), washed three times, and plated in uncoated tissue culture flasks at a density of $1.0 \times 10^{6} / \mathrm{ml}$ in serum-free F-12K. Twenty microliters of the 50-fold concentrated MAPC-conditioned medium were added per $1 \mathrm{ml}$ of serum-free F-12K medium, for a final concentration of $1 \times$. Before use in time-lapse experiments, the cultured cell line macrophages were harvested with EDTA and a cell scraper and resuspended in Neurobasal A with the addition of HEPES (50 $\mu \mathrm{m}$; SigmaAldrich) at a density of $2.5 \times 10^{5} / 70 \mu \mathrm{l}$.

Time-lapse microscopy. DRG neurons were incubated at $37^{\circ} \mathrm{C}$ for $48 \mathrm{~h}$ before time-lapse imaging. Neurobasal A medium with HEPES (50 $\mu \mathrm{M}$; Sigma-Aldrich) was added to the culture before transfer to a heated stage apparatus. Time-lapse images were acquired every $30 \mathrm{~s}$ for $3 \mathrm{~h}$ with a Zeiss Axiovert $405 \mathrm{M}$ microscope using a $100 \times$ oil-immersion objective. Growth cones were chosen that extended straight into the spot rim and had characteristic dystrophic morphology for 30 min to observe baseline behavior before the addition of cells or conditioned medium and then observed for 3 h. For cell addition experiments, cultured rat-derived MAPCs were harvested from tissue culture flasks, washed three times, and resuspended in Neurobasal A medium. For coculture experiments, MAPCs (100,000/dish) were added to dorsal root ganglia neuron cultures after $24 \mathrm{~h}$ and incubated at $37^{\circ} \mathrm{C}$ for 24 additional hours before time-lapse imaging. For experiments in which MAPC-CM was added to DRG cultures during time-lapse imaging, $90 \mu \mathrm{l}$ of $50 \times$ MAPC-CM was added after $30 \mathrm{~min}$ of baseline growth cone observation. MAPC-CMtreated macrophages were added to time-lapse cultures after $30 \mathrm{~min}$ of baseline imaging (500,000 cells/dish). Extension/retraction, rate of growth, turning, and branching were analyzed using MetaMorph software.

Immunocytochemistry. After time-lapse imaging, DRGs were fixed in $4 \%$ paraformaldehyde (PFA) and immunostained with anti-B-tubulintype III (1:500; Sigma-Aldrich), anti-chondroitin sulfate (CS-56; 1:500; Sigma-Aldrich), and anti-GFP (1:500; Invitrogen).

MMP-9 assays. NR8383 cells were cultured as described above, but in 24 -well plates at an initial density of $100,000 \mathrm{cells} / \mathrm{cm}^{2}$. MAPCs were cocultured with the NR8383 cells, via Transwells ( $0.4 \mu \mathrm{m}$; Costar), at an equal plating density. Negative control wells also received Transwell inserts, with an equivalent volume of medium, but no addition of MAPCs. 
After $24 \mathrm{~h}$, the Transwells and MAPCs were removed and discarded. NR8383 culture medium was removed, and the NR8383 cells were washed three times with PBS and refed with fresh medium containing no FBS. After an additional $24 \mathrm{~h}$, the NR8383 conditioned medium was collected for Western blot and zymogram analyses, and NR8383 total RNA was harvested for quantitative PCR analysis.

Western blotting. Total conditioned medium from two replicate wells was concentrated using the described centrifugal filters to a final volume of $\sim 20 \mu$ l. The total concentrated volume was loaded onto a $10 \%$ polyacrylamide gel (Bio-Rad; each gel lane represents total conditioned medium concentrated from two replicate wells), electrophoresed for $1-2 \mathrm{~h}$ at $100 \mathrm{~V}$, and transferred to polyvinylidene difluoride membrane (Immobilon membrane; Millipore). Western blots were blocked in Western Blocking Solution (Sigma-Aldrich) for $30 \mathrm{~min}$, and then incubated in primary antibody ( $\alpha$-MMP-9; AB19016; Millipore; 1:1000 dilution in blocking solution) for $2 \mathrm{~h}$ at room temperature. Western blots were washed four times in TBS and incubated in secondary antibody ( $\alpha$-rabbit IgG HRP; Promega; 1:2500 dilution in blocking solution) for $1 \mathrm{~h}$ at room temperature. Bound HRP-conjugated antibody was visualized using ECL chemiluminescence reagent (GE Healthcare) according to manufacturer's specifications, and imaged using a ChemiDoc-It imaging system (UVP). Background-subtracted band densitometry was measured and analyzed by Student's $t$ test for statistical significance.

Zymography. Total conditioned medium from two replicate wells was concentrated as described above and loaded onto a $10 \%$ gelatin zymogram gel (Bio-Rad) and electrophoresed for $1-2 \mathrm{~h}$ at $100 \mathrm{~V}$. Zymograms were washed in $2.5 \%$ Triton X-100 for $30 \mathrm{~min}$ and incubated overnight at $37^{\circ} \mathrm{C}$ in developing buffer (50 mM Tris, $200 \mathrm{~mm} \mathrm{NaCl}, 5 \mathrm{~mm} \mathrm{CaCl}_{2}, 0.02 \%$ Brij35). Zymograms were stained for $1 \mathrm{~h}$ (0.5\% Coomassie G250, 30\% methanol, $10 \%$ acetic acid) and destained (30\% methanol, $10 \%$ acetic acid) until bands were visualized. Zymograms were brightfield imaged using a ChemiDoc-It imaging system. Background-subtracted band densitometry was measured and analyzed by Student's $t$ test for statistical significance.

Quantitative PCR. RNA was isolated from NR8383 cells using RNEasy columns (QIAGEN) according to manufacturer's specifications. Rat reference RNA (Stratagene) was used as a positive control. Synthesis of cDNA was performed with M-MLV (Moloney murine leukemia virus) reverse transcriptase and random hexamers (Promega). Control reactions were performed without reverse transcriptase to control for genomic DNA contamination. SYBR Green quantitative PCR was performed using the following primers: MMP-9 forward, GCGCCAGCCGACTTATGT; MMP-9 reverse, AATCCTCTGCCAGCTGTGTGT; $\beta$-actin forward, AGCCCCCTCTGAACCCTAAG; $\beta$-actin reverse, CAACACAGCCTGGATGGCTAC; rat Arg1 forward, CAG CAG GAA CCC TGG ATG A; rat Arg1 reverse, AAA GGC GCT CCG ATA ATC TCT; rat iNOS forward, CAT CAG GTC GGC CAT TAC TGT; rat iNOS reverse, CCA GAT CCG GAA GTC ATG CT. Quantitative PCR was performed using an ABI 7500 with 9600 emulation. The PCR conditions were $50^{\circ} \mathrm{C}$ for $2 \mathrm{~min}, 95^{\circ} \mathrm{C}$ for $10 \mathrm{~min}$, and then 40 cycles of $95^{\circ} \mathrm{C}$ for $15 \mathrm{~s}$, $60^{\circ} \mathrm{C}$ for $1 \mathrm{~min}$. NR8383 MMP-9 quantitation was normalized to $\beta$-actin levels and expressed as percentage of rat reference MMP-9 signal.

Dorsal column crush lesion model. All animal procedures were performed in accordance with the guidelines and protocols of the Animal Resource Center at Case Western Reserve University. Adult female Sprague Dawley rats, 250-300 g, were anesthetized with inhaled isoflurane gas (2\%) for all surgical procedures. A T1 laminectomy was performed to expose the dorsal aspect of the C8 spinal cord segment. A durotomy was made bilaterally $0.75 \mathrm{~mm}$ from midline with a 30 gauge needle. A dorsal column crush lesion was then made by inserting Dumont no. 3 jeweler's forceps into the dorsal spinal cord at C8 to a depth of $1.0 \mathrm{~mm}$, squeezing the forceps, holding pressure for $10 \mathrm{~s}$, and repeating two additional times. Completion of the lesion was verified by observation of white matter clearing. The holes in the dura were then covered with gel film. The muscle layers were sutured with 4-0 nylon suture, and the skin was closed with surgical staples. On closing of the incision, animals received Marcaine $(1.0 \mathrm{mg} / \mathrm{kg})$ subcutaneously along the incision as well as buprenorphine $(0.1 \mathrm{mg} / \mathrm{kg})$ intramuscularly. Postoperatively, animals were kept warm with a heating lamp during recovery from anesthesia and allowed access to food and water ad libitum. Animals were killed at 2, 4, or $7 \mathrm{~d}$ after lesion.

Cell transplantation. Cultured rat-derived MAPCs were harvested from tissue culture flasks, washed three times in HBSS-CMF, and resuspended in HBSS-CMF at a density of 200,000 cells/ $\mu$ l. For astrocyte transplants, cells were labeled using Vybrant CFDA SE Cell Tracer Kit (Invitrogen) at $10 \mu \mathrm{M}$ for $15 \mathrm{~min}$ at $37^{\circ} \mathrm{C}$ and washed twice before resuspension in HBSS-CMF at a density of 200,000 cells/ $\mu$ l. Immediately after dorsal column crush injury, $1.0 \mu \mathrm{l}$ of the cell suspension was injected unilaterally $0.5 \mathrm{~mm}$ deep into the right side dorsal columns. The injection site was $0.5 \mathrm{~mm}$ lateral to the midline and $0.5 \mathrm{~mm}$ caudal to the lesion edge. The cells were injected with $4423.0 \mathrm{nl}$ pulses on $15 \mathrm{~s}$ intervals through a pulled glass pipette attached to a Nanoject II (Drummond). The glass pipette was then withdrawn from the spinal cord 2 min after the final injection. After the transplantation, the injection site was covered with gelfilm, the muscle layers were closed with 4-0 ethicon sutures, and the skin was closed with surgical staples. Postoperatively, animals were kept warm with a heating lamp during recovery from anesthesia and allowed access to food and water ad libitum. Animals were killed 2 or 4 or $7 \mathrm{~d}$ after lesion.

Axon labeling. Two days before rats were killed, the dorsal columns were labeled unilaterally with Texas Red-conjugated 3000 molecular weight (MW) dextran. Briefly, the sciatic nerve of the right hindlimb was exposed and crushed three times with Dumont no. 3 forceps for $10 \mathrm{~s}$. One microliter of $3000 \mathrm{MW}$ dextran-Texas Red (10\%) in sterile water was the injected via a Hamilton syringe into the sciatic nerve at the crush site. The muscle layers were closed with 4-0 nylon suture and the skin with surgical staples. On closing of the incision, animals received Marcaine $(1.0 \mathrm{mg} / \mathrm{kg})$ subcutaneously along the incision as well as buprenorphine $(0.1 \mathrm{mg} / \mathrm{kg})$ intramuscularly. Postoperatively, animals will be kept warm with a heating lamp during recovery from anesthesia and allowed access to food and water ad libitum. Animals were killed $2 \mathrm{~d}$ after labeling with an overdose of isoflurane and perfused with PBS followed by $4 \%$ PFA. Tissue was harvested and postfixed in $4 \%$ PFA and processed for immunohistochemistry.

Immunohistochemistry. Tissue was postfixed in 4\% PFA overnight and then submersed in $30 \%$ sucrose overnight, frozen in OTC mounting medium, and cut on a cryostat into $20 \mu \mathrm{m}$ longitudinal sections. Tissue was then stained with anti-ED1/Alexa Fluor 633, anti-GFP/Alexa Fluor 488, and anti-vimentin/Alexa Fluor 488, and imaged on a Zeiss Axiovert 510 laser-scanning confocal microscope at $10 \times$ magnification.

Axonal dieback quantification. To quantify axonal dieback, three consecutive sections per animal were analyzed, starting at a depth of $200 \mu \mathrm{m}$ below the dorsal surface of the spinal cord. The lesion center was identified via characteristic GFAP and/or vimentin staining patterns and then centered using Zeiss LSM 5 Image Browser software. The distance between the ends of five labeled axons projecting farthest into the lesion and the lesion center was then measured. The measurements from all sections from all animals in a group were averaged to yield the average distance of dieback per time point.

\section{Results}

We first sought to examine the effects of MAPCs on macrophagemediated axonal dieback using an in vitro system known as a spot assay. This assay involves culturing dissociated adult DRG neurons on an inhibitory gradient of the proteoglycan aggrecan. As DRG neurons that have adhered to the center of the spot extend axons into the gradient, they are met with increasing concentrations of proteoglycan, and concurrently with decreasing amounts of laminin, which results in the formation of dystrophic growth cones at the tips of the axons, a phenomenon that occurs in vivo after spinal cord injury (Tom et al., 2004). Once axons enter the dystrophic state, they are unable to traverse the most inhibitory outer rim of the substrate and instead remain stalled for extended periods of time, undergoing only slight forward extension or collapse.

To examine the effects of MAPCs on dystrophic axons in the inhibitory gradient, we added adult rat MAPCs to cultures of DRG neurons that had been growing on the spot assay for $24 \mathrm{~h}$ 

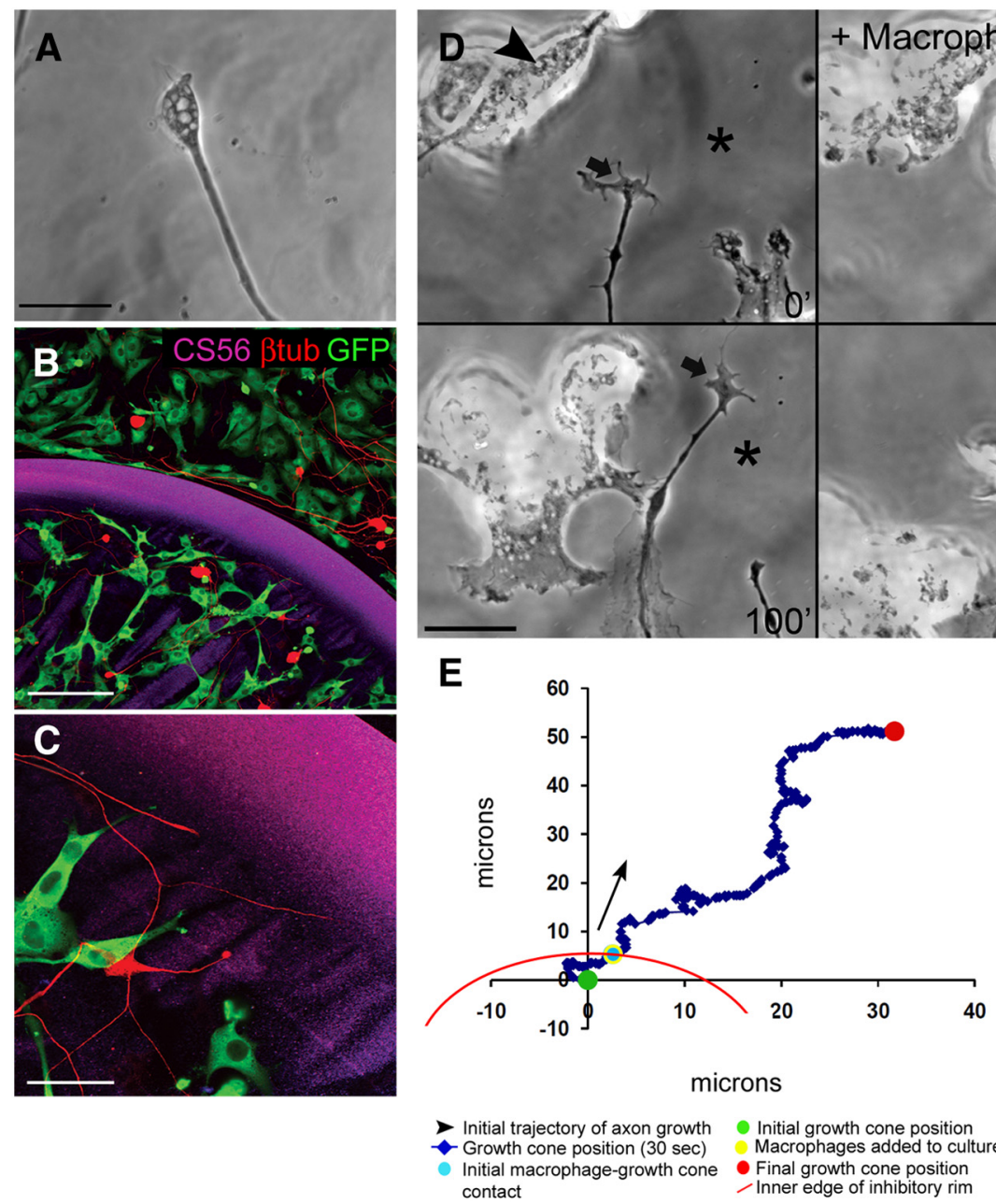

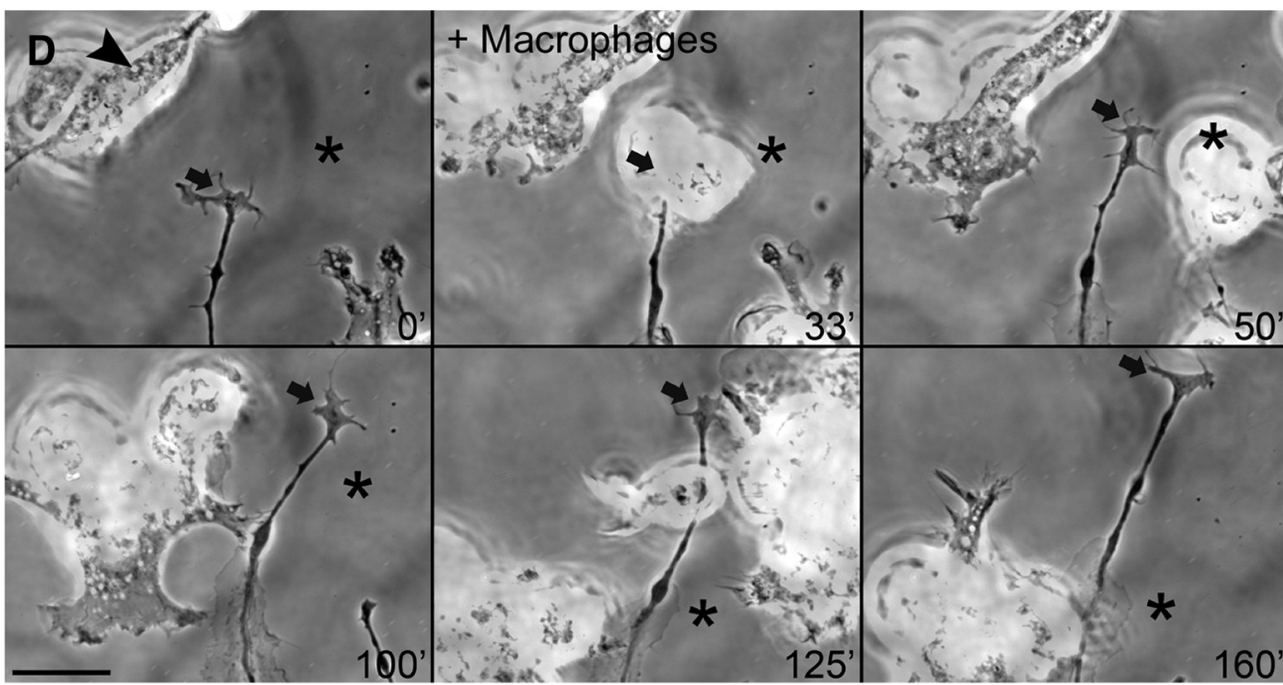

F Growth cone distance from the origin after macrophage-axon contact in coculture with MAPC

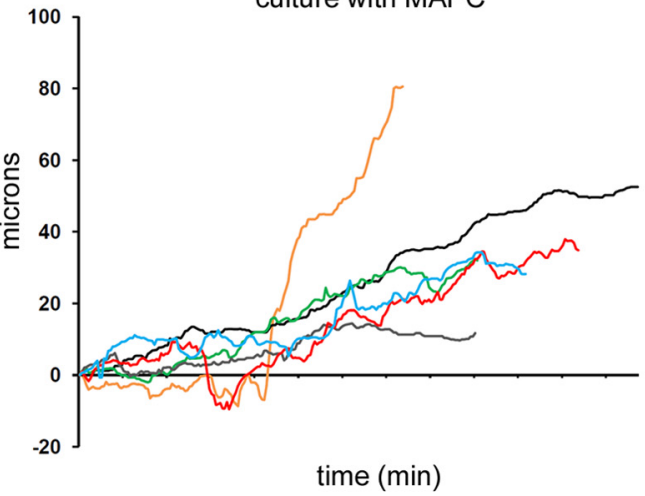

Figure 1. Coculture of adult sensory neurons with MAPCs can prevent macrophage-mediated axonal dieback. $A, A$ A $100 \times$ image of a typical dystrophic growth cone that forms in response to exposure to the inhibitory proteoglycan gradient. $B, A 10 \times$ confocal image of GFP + MAPCs (green) cultured on a gradient of proteoglycan (CS56; red). MAPCs added to the spot gradient did not invade the inhibitory rim, but adhered to the center of the spot and associated with adult DRG axons. $C, A 40 \times$ confocal image of image shown in $B$. Adult DRGs and MAPCs do not cross the inhibitory spot rim after $2 \mathrm{~d}$ in vitro. $D$, Six-panel montage of single-frame images from a time-lapse movie taken at $100 \times$ in which coculture with MAPCs prevents macrophage-mediated retraction of a DRG growth cone. Macrophages were added to a culture of dystrophic adult DRG neurons growing on a spot gradient of the inhibitory CSPG aggrecan. Times for each frame are given in the bottom right of each image, and an arrow marks the central domain of the growth cone. An arrowhead marks a MAPC growing alongside the axon that contacts it briefly in frame $100^{\prime}$. An asterisk marks a consistent point on the culture dish as a reference during frame shifts. $\boldsymbol{E}$, Positional graph tracking the growth cone for the time-lapse movie in $\boldsymbol{D}$. $\boldsymbol{F}$, Distance from the origin of six dystrophic axons on the proteoglycan/laminin spot gradient in coculture with MAPCs after contact with macrophages. Scale bars: $A, D, 20 \mu \mathrm{m} ; \boldsymbol{B}, 200 \mu \mathrm{m} ; \boldsymbol{C}, 50 \mu \mathrm{m}$.

(for a schematic of all in vitro experimental paradigms, see supplemental Fig. S1, available at www.jneurosci.org as supplemental material). After $1 \mathrm{~d}$ in coculture, neither adult rat MAPCs nor adult DRG neurons were able to cross the inhibitory spot rim (Fig. $1 B, C$ ), suggesting that MAPCs were not degrading the proteoglycan substrate. Dystrophic growth cones found within the inhibitory rim typically have a characteristic bulbous, highly vacuolated morphology (Fig. 1A). Growth cones of neurons cocultured with MAPCs were quite different, more dynamic and flattened with extensive lamellipodia and filopodia (Fig. 1D; supplemental Movie 1, available at www.jneurosci.org as supplemental material). Previous work from our laboratory demonstrated that, when dystrophic axons in the inhibitory spot rim are contacted by activated macrophages, they undergo dramatic long-distance retraction, otherwise known as dieback (Horn et al., 2008). Activated macrophages form tight, long-lasting adhesions with dystrophic axons that, along with MMP-9 secretion, are necessary for the induction of dieback (Busch et al., 2009). We therefore sought to examine the potential effects of coculturing DRG neurons with MAPCs on these phenomena. We selected and imaged dystrophic axons in the inhibitory rim and, after 30 min of baseline observation of growth cone behavior, added NR8383 macrophages to the coculture. Macrophages formed contacts with the axons and growth cones, but these were often transient and were rapidly broken. In the example shown, the growth cone continues to extend further into the inhibitory rim in the presence of MAPCs. Five of the six imaged axons in coculture with MAPCs did not undergo macrophage-mediated axonal retraction (Fig. 1D-F), whereas $100 \%$ of dystrophic growth cones typically undergo axonal dieback after macrophage attack (Horn et al., 2008). The ability of MAPCs to prevent axonal dieback could be attributable to stimulatory effects on the neuron, modulatory effects on the macrophages, or a combination of both. To address this question, we performed a series of conditioned-medium experiments. In the presence of control medium only, extensive physical interactions occurred between activated macrophages and dystrophic axons resulting in dramatic axonal dieback $(N=6$ of 6$)$ (Fig. $2 A-C)$. The growth cone shown here underwent lengthy retraction of $\sim 80 \mu \mathrm{m}$ beginning at $\sim 30 \mathrm{~min}$ after initial macrophage contact, demonstrating that 
control unconditioned MAPC medium is insufficient to prevent axonal dieback. Direct addition of MAPC-CM to the timelapse dish resulted in a dramatic change in growth cone morphology from a stalled, dystrophic state to a motile, flattened state (Fig. 3A; supplemental Movie 2, available at www.jneurosci.org as supplemental material). After addition of MAPC-CM, dystrophic axons were able to extend even further into the inhibitory rim and occasionally robust branching was observed (Fig. $3 A, C$ ). Axon extension occurred rapidly after exposure to MAPC-CM, suggesting that the effect is likely independent of transcription (Willis and Twiss, 2006). Macrophages still contacted these axons but did not induce axonal retraction (Fig. 3A-C). As a result of this remarkable short-term induction of sprouting and extension, we sought to determine the growth-promoting potential of MAPC-secreted factors over a period of $24 \mathrm{~h}$. We added either MAPC-CM or control medium (CM) to dissociated DRG neurons growing on low levels of laminin and measured the longest neurite on each neuron. We found that MAPC-CM significantly increased sensory neurite outgrowth over $\mathrm{CM}$ and basal medium conditions $(p<0.0001)$ (Fig. $4 A-C)$.

To determine whether MAPCsecreted factors were sufficient to modulate the retraction-inducing capabilities of macrophages, we pretreated macrophages with MAPC-CM for $24 \mathrm{~h}$ and then washed the macrophages before their addition to the neuronal cultures on the spot assay. We observed no obvious differences in the ability of MAPC-CM-pretreated macrophages to recognize and associate with dystrophic axons compared with untreated macrophages. Dystrophic axons did not extend significantly further into the inhibitory proteoglycan gradient as they had in the presence of MAPC-CM; however, macrophage-mediated axonal retraction still did not occur $(N=4$ of 4$)$ (Fig. $5 A-C$; supplemental Movie 3, available at www.jneurosci.org as supplemental material), indicating that MAPC-secreted factors were modulating the ability of the macrophages to induce dieback. Because macrophages still formed contacts with the axon, it did not appear that their ability to recognize the dystrophic/injured state or adhere to the axon was impaired, but this activity alone was insufficient to induce dieback after pretreatment with MAPCs.

Macrophages are known to secrete a variety of proteases, which aid in the breakdown and clearance of debris after injury (Yong, 2005). MMPs have been implicated in regeneration failure after CNS injury (Noble et al., 2002), and work from our laboratory has demonstrated that specific chemical inhibition of macrophage-produced MMP-9 can prevent axonal dieback (Busch et al., 2009). We therefore examined the effect of MAPCs on MMP-9 production and secretion from macrophages. We found that coculture with MAPCs dramatically reduced the secretion of both the $105 \mathrm{kDa}$ pro- and 95 $\mathrm{kDa}$ activated forms of MMP-9 by macrophages as measured by Western blot $(p<0.05$ ) (Fig. $6 A$ ) and levels of functional protein as measured by gelatin zymography $(p<0.05)$ (Fig. $6 B)$. Inhibition of MMP-9 proteolytic activity by binding of tissue inhibitor of metalloproteinases (TIMPs) is likely not a factor in the decreased MMP-9 levels observed by Western blot and zymogram, as the denaturing conditions present in these assays would disrupt any existing MMP-9/TIMP protein complexes. Quantitative PCR demonstrated that there was no change in macrophage transcript levels of MMP-9 as a result of coculture with MAPCs (supplemental Fig. S2, available at www.jneurosci.org as supplemental material). The effect was relatively specific to MAPCs as coculture of macrophages with NG2+ progenitor cells did not decrease macrophage MMP-9 secretion (supplemental Fig. S2, available at www. jneurosci.org as supplemental material).

Recent work has established that secretion of such proinflammatory molecules is reflective of the general activation state of macrophages and is decreased by shifting from an M1, or "classically activated" proinflammatory state, to an M2, or "alternatively activated" antiinflammatory state (Gordon, 2003). M1 macrophages release cytokines, reactive oxygen species, nitric oxide, and MMPs, whereas M2 macrophages are not neurotoxic, can promote neurite outgrowth (Block et al., 2007; Kigerl et al., 2009), and exhibit decreased production of a number of proinflammatory molecules, including MMP-9 (Chizzolini et al., 2000). There are several markers of M1 and M2 macrophages in 


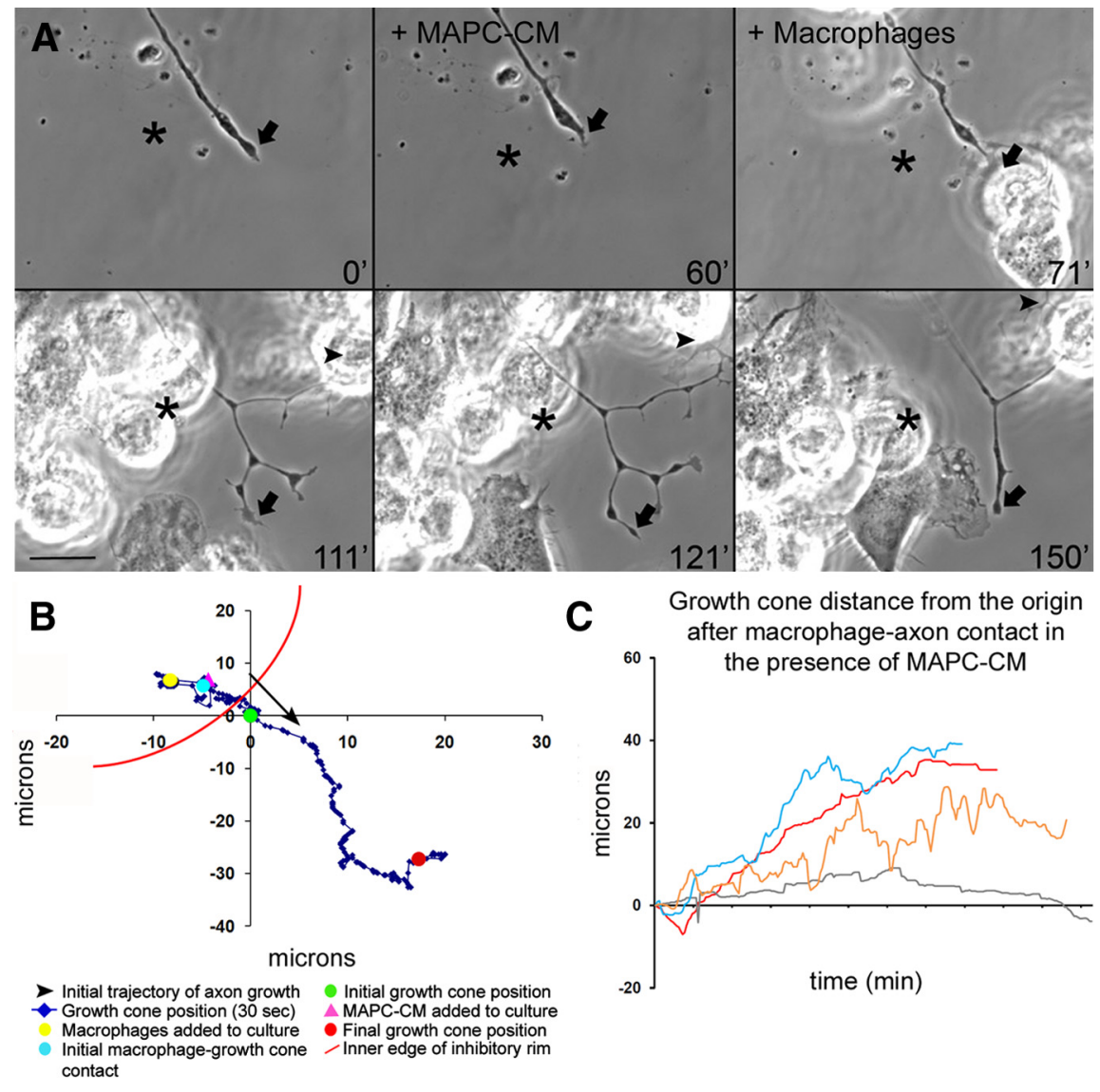

Figure 3. Macrophages do not induce dieback of dystrophic adult DRG axons in the presence of MAPC-CM. A, Six-panel montage of single-frame images, arranged as stated in Figure 1 legend, from a time-lapse movie in which MAPC-CM and macrophages were added to a culture of dystrophic adult DRG neurons growing on a spot assay of the inhibitory CSPG aggrecan. The arrowhead indicates a secondary growth cone that forms as the axon branches. Macrophages do not induce retraction of the dystrophic growth cone in the presence of MAPC-CM. An asterisk marks a consistent point on the culture dish as a reference during frame shifts. $\boldsymbol{B}$, Positional graph tracking the growth cone for entire time-lapse movie in $\boldsymbol{A}$. C, Distance from the origin of six dystrophic axons on the proteoglycan/laminin spot assay after contact with macrophages in the presence of MAPC-CM. Scale bar: $A, 20 \mu \mathrm{m}$.

effects of MAPC-secreted factors on macrophage expression of iNos and Arg1 transcripts, using a Transwell coculture system. We found that MAPC-secreted factors induced a greater than fivefold increase in the relative ratio of Arg1 to iNos transcript in macrophages (Fig. 6C), demonstrating that MAPCs are able to induce a shift from a proinflammatory $\mathrm{M} 1$ phenotype toward an antiinflammatory M2 phenotype.

We next investigated the effects of MAPCs on axonal dieback in vivo using an adult rat dorsal column crush model of spinal cord injury. The most dramatic phase of axonal dieback occurs between 2 and $7 \mathrm{~d}$ after lesion, which correlates spatiotemporally with the infiltration of activated macrophages into the lesion (Horn et al., 2008). We hypothesized that MAPCs would modulate activated macrophages and/or stimulate axonal growth within the lesion in such a way as to reduce the extent of axonal dieback and/or promote regeneration. Therefore, we transplanted MAPCs into the dorsal columns of the spinal cord immediately after injury and measured the extent of axonal dieback at 2, 4, and $7 \mathrm{~d}$ after lesion. MAPCs were transplanted $\sim 500 \mu \mathrm{m}$ caudal to the lesion and $500 \mu \mathrm{m}$ lateral to the midline to prevent the cells from being displaced from the spinal cord by blood and CSF flow directly at the lesion site. MAPCs survived in large numbers when transplanted in the acute post lesion interval but were ultimately cleared by $28 \mathrm{~d}$ after injury (data not shown), enabling the cells to effect the lesion environment for some time, while minimizing the risk of any remaining cells contrib-

\section{A}
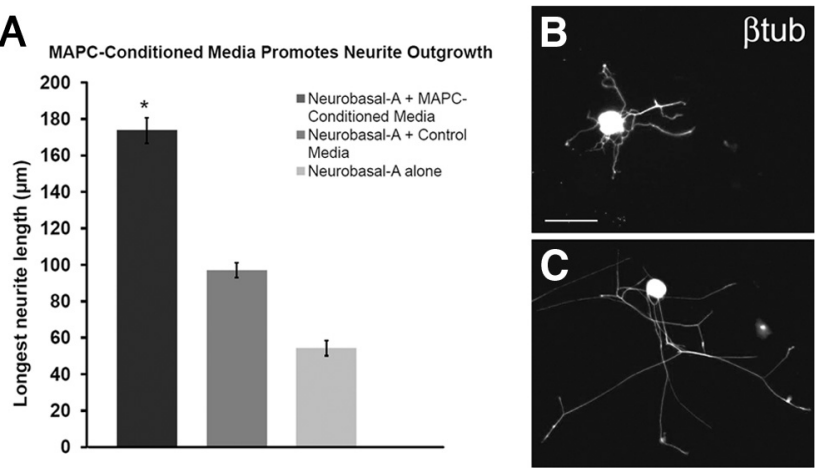

Figure 4. MAPC-CM treatment of adult DRGs promotes neurite outgrowth on $5 \mu \mathrm{g} / \mathrm{ml}$ lami$\operatorname{nin} . \boldsymbol{A}$, The longest axon from each dissociated DRG was measured for the group to which medium containing Neurobasal $A$ and either MAPC-CM, control medium, or no medium were added. All conditions are significant from one another (one-way ANOVA, ${ }^{*} p<0.0001$ ). Error bars indicate SEM. B, A $16 \times$ image representing the average amount of outgrowth of an untreated DRG neuron. $C, A 16 \times$ image representing the average amount of outgrowth of $D R G S$ pretreated with MAPC-conditioned medium. Scale bars: $B, C, 40 \mu \mathrm{m}$.

vitro and in vivo, some of the most well studied of which are inducible nitric oxide synthase (iNos), a marker of M1 macrophages, and arginase 1 (Arg1), a marker of M2 macrophages (Gordon, 2003; Ghassabeh et al., 2006; Kigerl et al., 2009). We therefore examined the uting to ectopic tissue formation or aberrant physiology.

Transplanted MAPCs migrated extensively from the site of transplantation into the core of the lesion and were observed to associate with the endings of injured axons (Fig. 7B; supplemental Fig. S4, available at www.jneurosci.org as supplemental material). By $2 \mathrm{~d}$ after lesion, macrophages were not yet present in the lesion in significant numbers, but labeled axons did not extend to the edge of the lesion. This suggests that an initial, intrinsic, macrophage-independent phase of dieback occurs during this time, which has previously been demonstrated by Kerschensteiner et al. (2005). Accordingly, the extent of axonal dieback in MAPC-transplanted animals was similar to that observed in vehicle control-treated animals at $2 \mathrm{~d}$ after lesion (Fig. 7C). By $4 \mathrm{~d}$ after lesion, MAPC-transplanted animals showed a significant decrease in the extent of axonal dieback compared with vehicle controls $(p<0.02)$ (Fig. $7 C)$. This is consistent with the idea that transplanted MAPCs attenuated the extent of axonal dieback that would normally occur at this time. Interestingly, MAPCtransplanted animals had decreased numbers of ED1+ cell profiles in the lesion core at both 4 and $7 \mathrm{~d}$ after lesion $(p<0.01)$ (Fig. $7 D)$. By $7 \mathrm{~d}$ after lesion, injured axons in MAPC-transplanted animals had regenerated into the lesion center, whereas axons in vehicle control-treated animals did not $(p<0.00001)$ (Fig. $7 A-C)$. In animals receiving MAPC transplants, we even observed fibers extending beyond the midpoint of the lesion at 
$7 \mathrm{~d}$ after injury $(p<0.01)$ (supplemental Fig. S4, available at www.jneurosci. org as supplemental material), providing additional evidence of the trophic and axon growth-supporting properties of this cell population.

To determine whether this result was attributable to common secreted factors and could be recapitulated by any cell type, we examined the effects of rat astrocyte transplants on axonal dieback at $7 \mathrm{~d}$ after injury. We chose to transplant astrocytes as they are resident CNS cells found in the lesion environment that do not induce axonal dieback in vitro (Horn et al., 2008). We found that astrocytes transplanted just outside the lesion also survived within the acute injury environment, but did not migrate extensively into the lesion core and were not able to prevent axonal dieback at $7 \mathrm{~d}$ after injury (supplemental Fig. S5, available at www.jneurosci.org as supplemental material). This suggests that our results with MAPCs are not simply the result of the physical presence of any cell type transplanted into the lesion.

\section{Discussion}

It was originally thought that transplantation of stem cells in the CNS would have beneficial effects primarily through replacement of damaged neuronal circuitry or promotion of reparative activities such as replenishment of lost oligodendrocytes and subsequent remyelination (Keirstead et al., 2005). However, several studies have found that, without manipulation, transplanted stem cells predominantly give rise to astrocytes, and limited numbers of oligodendrocytes and neurons (Hofstetter et al., 2005; Enzmann et al., 2006; KarimiAbdolrezaee et al., 2010). More recently, there is increasing evidence that transplanted adult stem cells tend to remain undifferentiated and often are cleared after a short time, but still promote recovery (Parr et al., 2007). This suggests that their beneficial effects are mediated primarily through paracrine activities that impact host tissues. This has been attributed to mechanisms involving release of factors that are neuroprotective (Parr et al., 2007), angiogenic (Onda et al., 2008), and/or immunomodulatory (Ohtaki et al., 2008; Abrams et al., 2009; Boucherie and Hermans, 2009). In this study, we have provided evidence that MAPCs can modulate macrophage responses to CNS injury and induce neurite outgrowth in vitro and, in turn, prevent the deleterious phenomenon of axonal dieback and promote regrowth after spinal cord injury.

Many previous experimental efforts to promote regeneration in the CNS have focused on eliminating or overcoming
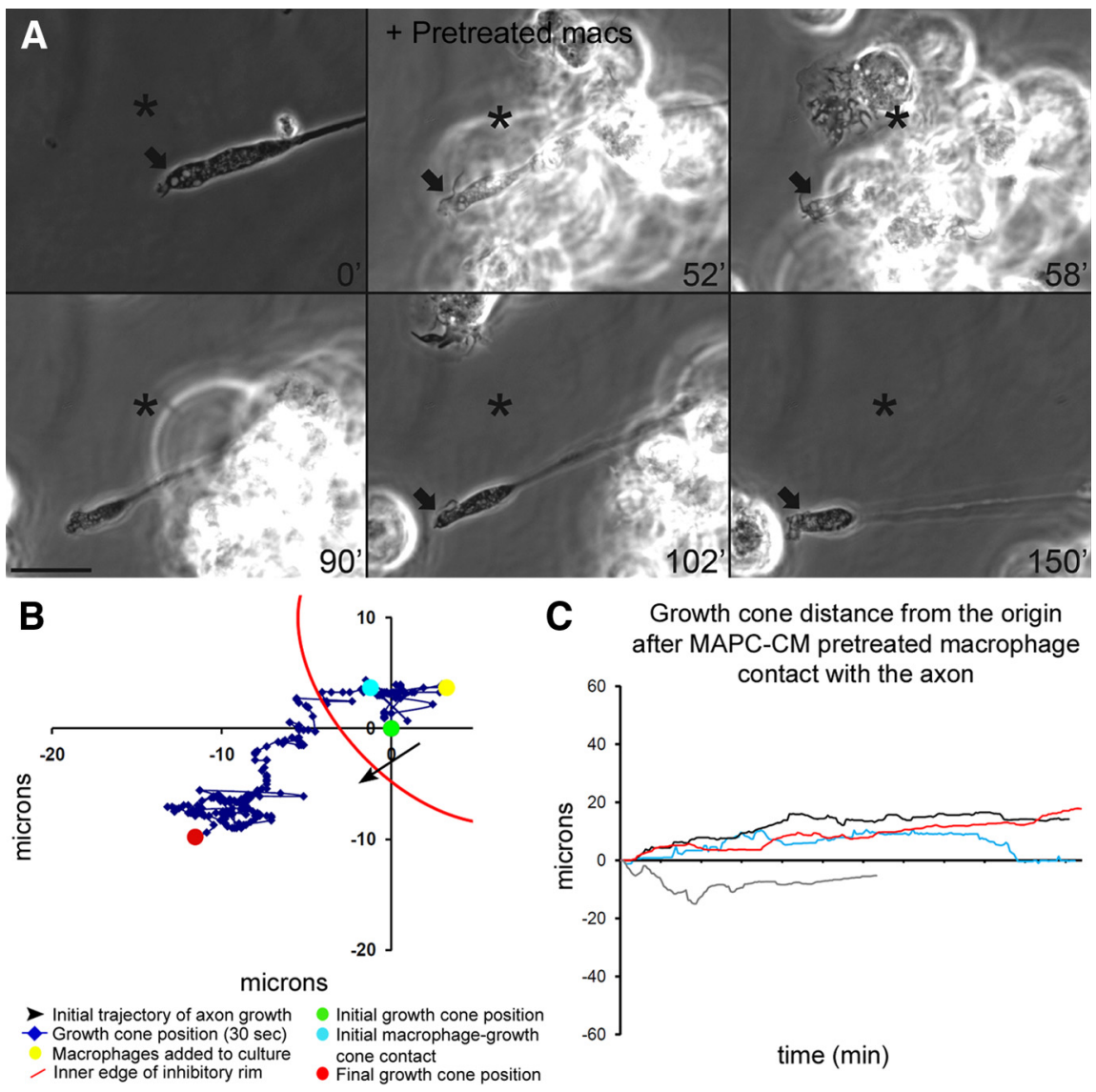

C Growth cone distance from the origin after MAPC-CM pretreated macrophage

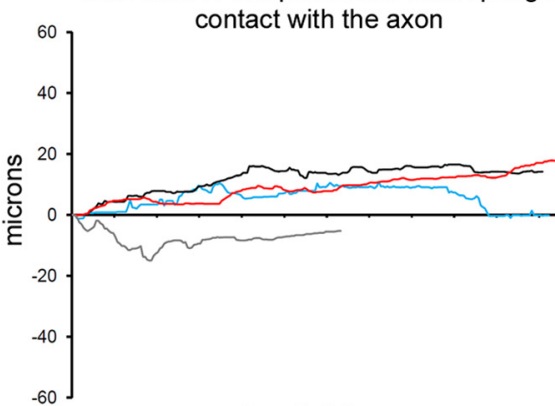

time $(\mathrm{min})$

Figure 5. MAPC-CM-pretreated macrophages do not induce dieback of dystrophic adult dorsal root ganglion axons. A, Six-panel montage of single-frame images from a time-lapse movie, arranged as stated in Figure 1 legend, in which MAPC-CM-pretreated NR8383 macrophages were added to a culture of dystrophic adult DRG neurons growing on a spot assay containing the inhibitory CSPG aggrecan arranged as stated in Figure 1 legend. MAPC-CM-treated macrophages do not induce retraction of the dystrophic growth cone. An asterisk marks a consistent point on the culture dish as a reference during frame shifts. $\boldsymbol{B}$, Positional graph tracking the growth cone for entire time-lapse movie in $\boldsymbol{A}$. Each point represents the position of the central domain of the growth cone for a single frame (every $30 \mathrm{~s}$ ). C, Distance from the origin of four dystrophic axons on the proteoglycan/laminin spot assay after contact with macrophages pretreated with MAPC-CM. Scale bar: $A, 20 \mu \mathrm{m}$.
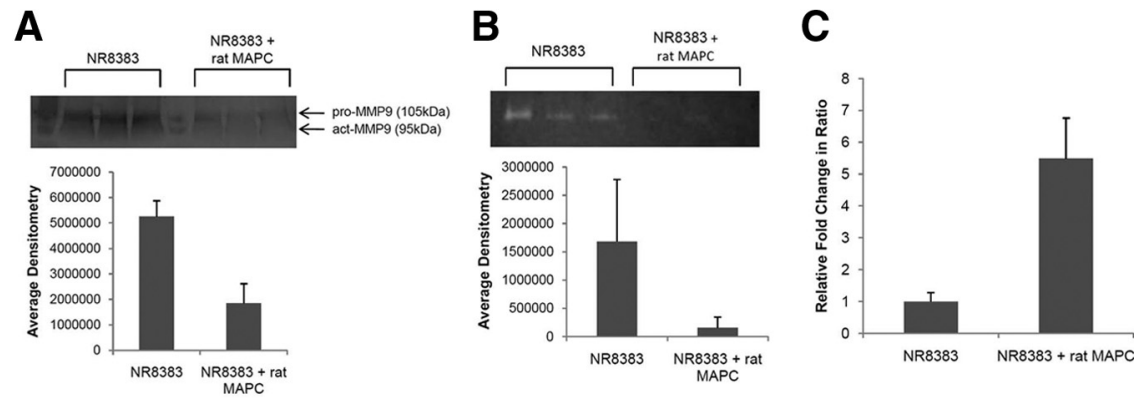

Figure 6. MAPCs alter expression and secretion of MMP-9 from macrophages and induce a shift from $M 1$ to $M 2$ markers of macrophage activation. $\boldsymbol{A}$, Western blot and densitometry quantification of MMP-9 levels in NR8383 macrophages in the presence or absence of MAPCS. $\boldsymbol{B}$, Zymography and densitometry of MMP-9 secretion from NR8383 macrophages in the presence or absence of MAPCs. $\boldsymbol{C}$, Relative fold change in the ratio of Arg1 to iNos transcript in macrophages in the presence of MAPCs. Error bars indicate SEM.

the barriers to regeneration individually through several approaches including the following: removal of inhibitors within the extracellular matrix (Silver and Miller, 2004), addition of growth factors (Alto et al., 2009), modification of the inflammatory response to injury (Horn et al., 2008; Gensel et al., 2009), as well as administration of conditioning lesions or placement of bridges to stimulate or direct the intrinsic growth capacity of neurons (David 

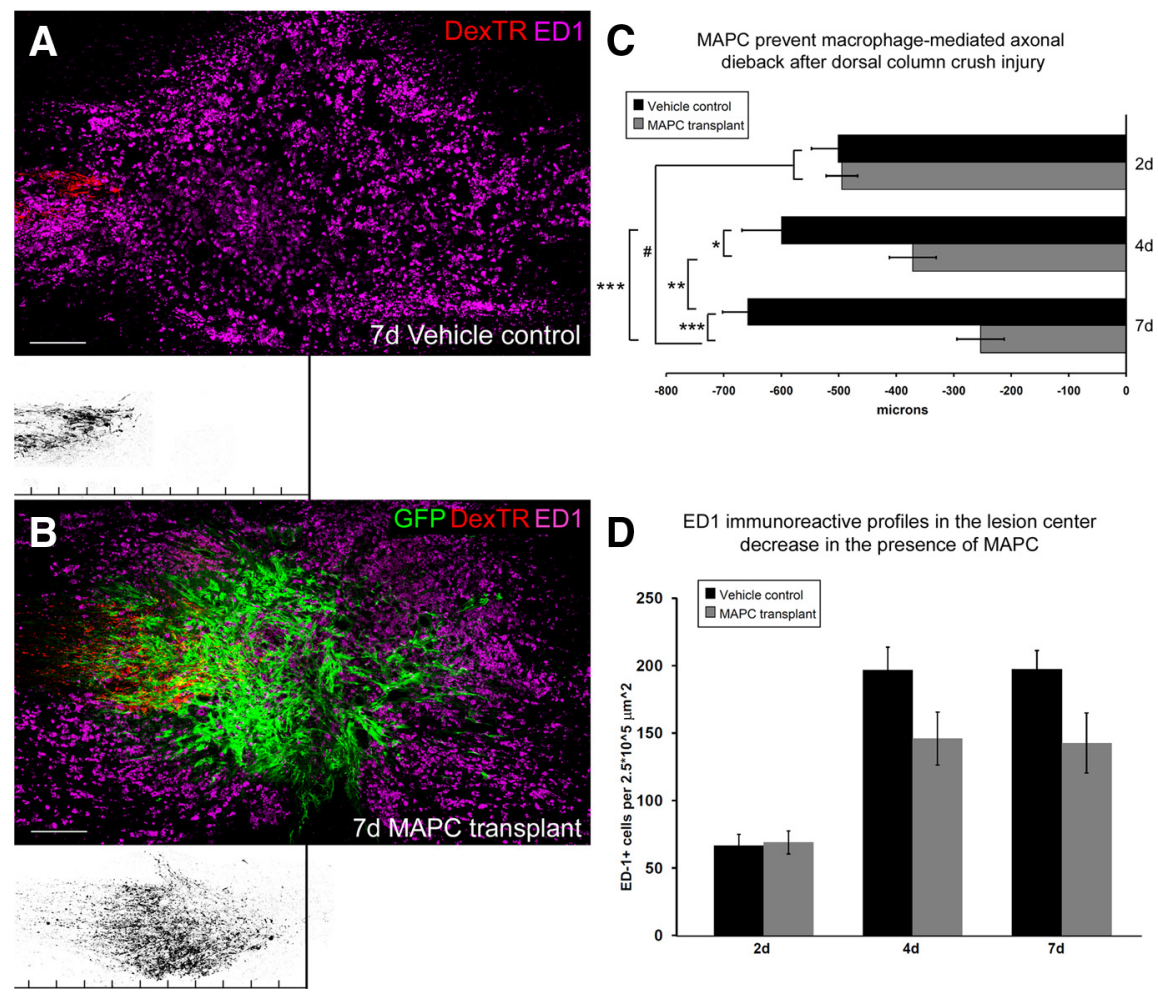

DD1 immunoreactive profiles in the lesion center

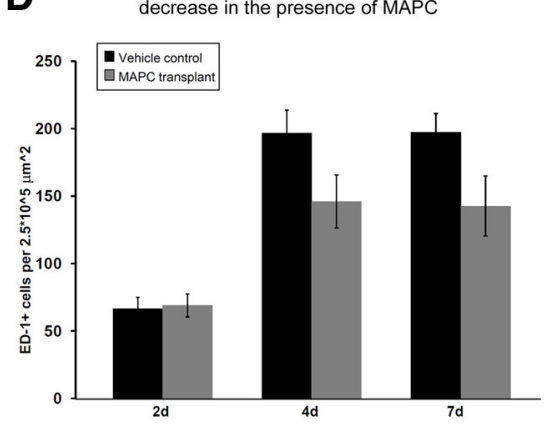

Figure 7. MAPCs prevent axonal dieback and promote growth into the lesion core after spinal cord injury. Shown are $10 \times$ image montages of 20 - $\mu$ m-thick longitudinal sections of a dorsal column crush spinal cord injury at $7 \mathrm{~d}$ after lesion. Fibers are labeled with Texas Red-conjugated 3000 MW dextran (DexTR) and macrophages are visualized with ED1+ (purple). The orientation of the sections is such that caudal is on the left side of the image and rostral is on the right. The lesion center is marked below (solid black lines) with three superimposed fiber tracings of multiple sections from one animal for each condition. $\boldsymbol{A}$, At $7 \mathrm{~d}$ after lesion and vehicle injection only, dorsal root ganglion axons (red) have retracted extensively from the initial site of axotomy. Below is an inverted grayscale image of three superimposed adjacent sections of DexTR-labeled fibers. Ruler tick marks are $100 \mu \mathrm{m}$ each and a solid line marks the lesion center. $\boldsymbol{B}$, By $7 \mathrm{~d}$ after lesion and GFP + MAPC transplant, injured axons have regenerated into the lesion in large numbers. $\boldsymbol{C}$, Graph indicating average axonal retraction over 2, 4, and $7 \mathrm{~d}$ after injury in animals receiving vehicle control or MAPC transplants. $N=4$ animals for each condition at each time point. The conditions, vehicle control and MAPCtreated groups, are significantly different from one another ( $p<0.0001$; two-way ANOVA, $\left.F_{(1,66)}=31.60\right)$. Day 2 vehicle control is significant from day 7 vehicle control; day 2 MAPC is significant from day 7 MAPC; day 4 vehicle control is significant from day 4 MAPC-treated and day 7 MAPC-treated groups; day 7 vehicle control group is significant from day 4 MAPC and day 7 MAPC groups by Tukey's post hoc test, ${ }^{\#} p<0.01,{ }^{*} p<0.02,{ }^{* *} p<0.001,{ }^{* * *} p<0.0001$. D, Graphical representation of ED1+ immunoreactivity in the center of the lesion at 2, 4, and $7 \mathrm{~d}$ after injury in animals receiving vehicle only or MAPC transplants. The conditions, vehicle control and MAPC-treated groups, are significantly different from one another $\left(p<0.01\right.$; two-way ANOVA, $F_{(1,66)}=$ 7.05). Error bars indicate SEM. Scale bars: $\boldsymbol{A}, \boldsymbol{B}, 200 \mu \mathrm{m}$.

and Aguayo, 1981; Neumann and Woolf, 1999; Houle et al., 2006; Park et al., 2008). More recently, it has been demonstrated that combinatorial strategies that target the numerous mechanisms involved in regeneration failure produce the best outcomes (Pearse et al., 2004; Kadoya et al., 2009). Here, we have shown that MAPCs can positively alter both the low intrinsic growth state of dystrophic adult sensory axons as well as the inflammatory response after injury to simultaneously prevent deleterious axonal dieback and promote neurite outgrowth and sprouting. Although the rescue of axonal dieback in MAPC-treated animals is spatially and temporally correlated with macrophage infiltration, and elimination of infiltrating macrophages has previously been shown to prevent axonal dieback during this time (Horn et al., 2008), we have not directly proven in this study that modulation of macrophage activity was the primary mechanism of action of MAPCs in the spinal cord. MAPCs could also influence axon outgrowth by altering other components of the lesion environment such as the glial scar through modification of astrocyte reactivity, possibly as a secondary effect of immunomodulation (Fitch et al., 1999). Additionally, production of trophic factors such as VEGF (vascular endothelial growth factor) by MAPCs (Van't Hof et al., 2007) could be contributing to a positive outcome by enhancing cell survival or promoting the recruitment and/or proliferation of endogenous progenitor cells (Engel and Wolswijk, 1996; Sasaki et al., 2009; Thau-Zuchman et al., 2010), which have been shown to provide a permissive substrate for regenerating axons (McTigue et al., 2001; Jones et al., 2003; Yang et al., 2006; Busch et al., 2010). Despite the fact that astrocytes were unable to prevent axonal dieback, we do not intend to suggest that these results will be unique to MAPC transplants. This will require extensive additional studies, and it is likely that other cell types will have the capacity to accomplish one or both to some extent. However, to our knowledge, this is the first demonstration of an adult stem cell capable of modulating a multiplicity of detrimental macrophage and neuronal behaviors concurrently.

Here, we have demonstrated that MAPCs can alter the inflammatory response to prevent, at least in part, deleterious secondary injury in the CNS. MAPC coculture with macrophages inhibits macrophage secretion of the protease MMP-9, which we have previously shown to be responsible, in part, for macrophage-induced axonal dieback (Busch et al., 2009). There are multiple stages of macrophage MMP-9 production and processing that could be impacted by MAPCs, including transcription, translation, secretion, activation, and inhibition by TIMPs. MAPC coculture could affect macrophage MMP-9 activity at any one, or more, of these levels. However, our data clearly demonstrate that MMP-9 transcription is not affected by MAPC coculture, as macrophage MMP-9 mRNA levels were unchanged in the presence of MAPCs compared with control conditions. Our data also indicate that activation of pro-MMP-9 is not affected by MAPC coculture, as both the pro- and activated forms of MMP-9 protein are proportionally decreased after coculture as seen by Western blot. Interestingly, TIMP-mediated inhibition might represent a secondary level at which MAPCs could further affect MMP-9 activity in dieback assays or in vivo, as MAPCs express high levels of TIMP-1 (data not shown). Nevertheless, our data indicate that MAPC coculture significantly reduced the amount of MMP-9 protein released by the cells, suggesting a direct effect on MMP-9 secretion. We have demonstrated the effects of MAPCs on MMP-9 activity and M1/M2 activation state markers; however, MAPCs may also alter expression of other MMPs and/or other proinflammatory molecules (Kigerl et al., 2009). Although MMPs are produced by both M1 and M2 macrophages, M2 macrophages have been shown to secrete MMP1 and MMP12, which favor substrate remodeling, and to downregulate MMP-9 (Gordon, 2003). A more detailed investigation of the effects of MAPCs on these processes will be required to fully understand the under- 
lying mechanism(s) and determine that these changes are also occurring in vivo. In the present study, we have laid the groundwork to examine this and other in vitro and in vivo pathways through which adherent stem cells control the macrophage inflammatory response to dystrophic neurons and the greater inflammatory environment.

MAPCs could have similar effects in other CNS injuries in which secondary injury has dire consequences, as has been suggested by other work (Zhao et al., 2002; Yasuhara et al., 2008). In the white matter of the dorsal columns, additional functional loss caused by dieback is not always evident unless axons retract past many collateral branch points (Seif et al., 2007). After ischemic lesion to the cortex, cortical projection fibers retract dramatically into white matter (A. L. Hawthorne and J. Silver, unpublished observations). Our results may therefore be particularly relevant after ischemic stroke, as regulating the extent of dieback in gray matter could significantly alter outcome. It is important to consider the spectrum of reparative pathways that can be engaged using cell therapy, particularly in light of many failed single modality approaches in stroke (Fisher et al., 2005). MAPCs could promote maintenance of cortical association as well as other types of fibers at the lesion edge, providing an enriched, synaptically connected lesion penumbra and an anatomical substrate for functional recovery.

Although significant work remains before these results can be translated to human therapy, it is exciting that several well characterized mechanistic pathways that mediate regeneration failure after spinal cord injury can be modified by a stem cell population. An allogeneic adult human bone marrow-derived stem cell, which uses MAPC growth conditions and is expanded under good manufacturing practice regulations, has already received allowance by the Food and Drug Administration for clinical investigation in the treatment of several indications, including ischemic stroke. Although combinatorial strategies using drugs or biologics are feasible, the dynamic and multimodal response of therapeutic stem cells to the injury environment may provide a safe and effective cellular therapy for spinal cord injury as well as other neurological indications.

\section{References}

Abrams MB, Dominguez C, Pernold K, Reger R, Wiesenfeld-Hallin Z, Olson L, Prockop D (2009) Multipotent mesenchymal stromal cells attenuate chronic inflammation and injury-induced sensitivity to mechanical stimuli in experimental spinal cord injury. Restor Neurol Neurosci 27:307-321.

Alto LT, Havton LA, Conner JM, Hollis Ii ER, Blesch A, Tuszynski MH (2009) Chemotropic guidance facilitates axonal regeneration and synapse formation after spinal cord injury. Nat Neurosci 12:1106-1113.

Bambakidis NC, Butler J, Horn EM, Wang X, Preul MC, Theodore N, Spetzler RF, Sonntag VK (2008) Stem cell biology and its therapeutic applications in the setting of spinal cord injury. Neurosurg Focus 24:E20.

Barnabé-Heider F, Frisén J (2008) Stem cells for spinal cord repair. Cell Stem Cell 3:16-24

Biernaskie J, Sparling JS, Liu J, Shannon CP, Plemel JR, Xie Y, Miller FD, Tetzlaff W (2007) Skin-derived precursors generate myelinating Schwann cells that promote remyelination and functional recovery after contusion spinal cord injury. J Neurosci 27:9545-9559.

Block ML, Zecca L, Hong JS (2007) Microglia-mediated neurotoxicity: uncovering the molecular mechanisms. Nat Rev Neurosci 8:57-69.

Boucherie C, Hermans E (2009) Adult stem cell therapies for neurological disorders: benefits beyond neuronal replacement? J Neurosci Res 87:1509-1521.

Busch SA, Horn KP, Silver DJ, Silver J (2009) Overcoming macrophagemediated axonal dieback following CNS injury. J Neurosci 29:9967-9976.

Busch SA, Horn KP, Cuascut FX, Hawthorne AL, Bai L, Miller RH, Silver J (2010) Adult NG2 + cells are permissive to neurite outgrowth and stabi- lize sensory axons during macrophage-induced axonal dieback after spinal cord injury. J Neurosci 30:255-265.

Caplan AI, Dennis JE (2006) Mesenchymal stem cells as trophic mediators. J Cell Biochem 98:1076-1084.

Chizzolini C, Rezzonico R, De Luca C, Burger D, Dayer JM (2000) Th2 cell membrane factors in association with IL-4 enhance matrix metalloproteinase-1 (MMP-1) while decreasing MMP-9 production by granulocyte-macrophage colony-stimulating factor-differentiated human monocytes. J Immunol 164:5952-5960.

David S, Aguayo AJ (1981) Axonal elongation into peripheral nervous system "bridges" after central nervous system injury in adult rats. Science 214:931-933.

Eftekharpour E, Karimi-Abdolrezaee S, Fehlings MG (2008) Current status of experimental cell replacement approaches to spinal cord injury. Neurosurg Focus 24:E19.

Engel U, Wolswijk G (1996) Oligodendrocyte-type-2 astrocyte (O-2A) progenitor cells derived from adult rat spinal cord: in vitro characteristics and response to PDGF, bFGF and NT-3. Glia 16:16-26.

Enzmann GU, Benton RL, Talbott JF, Cao Q, Whittemore SR (2006) Functional considerations of stem cell transplantation therapy for spinal cord repair. J Neurotrauma 23:479-495.

Fisher M, Albers GW, Donnan GA, Furlan AJ, Grotta JC, Kidwell CS, Sacco RL, Wechsler LR (2005) Enhancing the development and approval of acute stroke therapies: Stroke Therapy Academic Industry roundtable. Stroke 36:1808-1813.

Fitch MT, Doller C, Combs CK, Landreth GE, Silver J (1999) Cellular and molecular mechanisms of glial scarring and progressive cavitation: in vivo and in vitro analysis of inflammation-induced secondary injury after CNS trauma. J Neurosci 19:8182-8198.

Gensel JC, Nakamura S, Guan Z, van Rooijen N, Ankeny DP, Popovich PG (2009) Macrophages promote axon regeneration with concurrent neurotoxicity. J Neurosci 29:3956-3968.

Ghassabeh GH, De Baetselier P, Brys L, Noël W, Van Ginderachter JA, Meerschaut S, Beschin A, Brombacher F, Raes G (2006) Identification of a common gene signature for type II cytokine-associated myeloid cells elicited in vivo in different pathologic conditions. Blood 108:575-583.

Gnecchi M, Zhang Z, Ni A, Dzau VJ (2008) Paracrine mechanisms in adult stem cell signaling and therapy. Circ Res 103:1204-1219.

Gordon S (2003) Alternative activation of macrophages. Nat Rev Immunol 3:23-35.

Hofstetter CP, Holmström NA, Lilja JA, Schweinhardt P, Hao J, Spenger C, Wiesenfeld-Hallin Z, Kurpad SN, Frisén J, Olson L (2005) Allodynia limits the usefulness of intraspinal neural stem cell grafts; directed differentiation improves outcome. Nat Neurosci 8:346-353.

Horn KP, Busch SA, Hawthorne AL, van Rooijen N, Silver J (2008) Another barrier to regeneration in the CNS: activated macrophages induce extensive retraction of dystrophic axons through direct physical interactions. J Neurosci 28:9330-9341.

Houle JD, Tom VJ, Mayes D, Wagoner G, Phillips N, Silver J (2006) Combining an autologous peripheral nervous system "bridge" and matrix modification by chondroitinase allows robust, functional regeneration beyond a hemisection lesion of the adult rat spinal cord. J Neurosci 26:7405-7415.

Jiang Y, Jahagirdar BN, Reinhardt RL, Schwartz RE, Keene CD, OrtizGonzalez XR, Reyes M, Lenvik T, Lund T, Blackstad M, Du J, Aldrich S, Lisberg A, Low WC, Largaespada DA, Verfaillie CM (2002a) Pluripotency of mesenchymal stem cells derived from adult marrow. Nature 418:41-49.

Jiang Y, Vaessen B, Lenvik T, Blackstad M, Reyes M, Verfaillie CM (2002b) Multipotent progenitor cells can be isolated from postnatal murine bone marrow, muscle, and brain. Exp Hematol 30:896-904.

Jones LL, Sajed D, Tuszynski MH (2003) Axonal regeneration through regions of chondroitin sulfate proteoglycan deposition after spinal cord injury: a balance of permissiveness and inhibition. J Neurosci 23:9276-9288

Kadoya K, Tsukada S, Lu P, Coppola G, Geschwind D, Filbin MT, Blesch A, Tuszynski MH (2009) Combined intrinsic and extrinsic neuronal mechanisms facilitate bridging axonal regeneration one year after spinal cord injury. Neuron 64:165-172.

Karimi-Abdolrezaee S, Eftekharpour E, Wang J, Schut D, Fehlings MG (2010) Synergistic effects of transplanted adult neural stem/progenitor 
cells, chondroitinase, and growth factors promote functional repair and plasticity of the chronically injured spinal cord. J Neurosci 30:1657-1676.

Keirstead HS, Nistor G, Bernal G, Totoiu M, Cloutier F, Sharp K, Steward O (2005) Human embryonic stem cell-derived oligodendrocyte progenitor cell transplants remyelinate and restore locomotion after spinal cord injury. J Neurosci 25:4694-4705.

Kerschensteiner M, Schwab ME, Lichtman JW, Misgeld T (2005) In vivo imaging of axonal degeneration and regeneration in the injured spinal cord. Nat Med 11:572-577.

Kigerl KA, Gensel JC, Ankeny DP, Alexander JK, Donnelly DJ, Popovich PG (2009) Identification of two distinct macrophage subsets with divergent effects causing either neurotoxicity or regeneration in the injured mouse spinal cord. J Neurosci 29:13435-13444.

Kovacsovics-Bankowski M, Streeter PR, Mauch KA, Frey MR, Raber A, van't Hof W, Deans R, Maziarz RT (2009) Clinical scale expanded adult pluripotent stem cells prevent graft-versus-host disease. Cell Immunol 255:55-60.

Mays RW, van't Hof W, Ting AE, Perry R, Deans R (2007) Development of adult pluripotent stem cell therapies for ischemic injury and disease. Expert Opin Biol Ther 7:173-184.

McTigue DM, Wei P, Stokes BT (2001) Proliferation of NG2-positive cells and altered oligodendrocyte numbers in the contused rat spinal cord. J Neurosci 21:3392-3400.

Neumann S, WoolfCJ (1999) Regeneration of dorsal column fibers into and beyond the lesion site following adult spinal cord injury. Neuron 23:83-91.

Noble LJ, Donovan F, Igarashi T, Goussev S, Werb Z (2002) Matrix metalloproteinases limit functional recovery after spinal cord injury by modulation of early vascular events. J Neurosci 22:7526-7535.

Ohtaki H, Ylostalo JH, Foraker JE, Robinson AP, Reger RL, Shioda S, Prockop DJ (2008) Stem/progenitor cells from bone marrow decrease neuronal death in global ischemia by modulation of inflammatory/immune responses. Proc Natl Acad Sci U S A 105:14638-14643.

Onda T, Honmou O, Harada K, Houkin K, Hamada H, Kocsis JD (2008) Therapeutic benefits by human mesenchymal stem cells (hMSCs) and Ang-1 gene-modified hMSCs after cerebral ischemia. J Cereb Blood Flow Metab 28:329-340.

Park KK, Liu K, Hu Y, Smith PD, Wang C, Cai B, Xu B, Connolly L, Kramvis I, Sahin M, He Z (2008) Promoting axon regeneration in the adult CNS by modulation of the PTEN/mTOR pathway. Science 322:963-966.

Parr AM, Tator CH, Keating A (2007) Bone marrow-derived mesenchymal stromal cells for the repair of central nervous system injury. Bone Marrow Transplant 40:609-619.

Pearse DD, Pereira FC, Marcillo AE, Bates ML, Berrocal YA, Filbin MT, Bunge MB (2004) cAMP and Schwann cells promote axonal growth and functional recovery after spinal cord injury. Nat Med 10:610-616.
Sasaki M, Radtke C, Tan AM, Zhao P, Hamada H, Houkin K, Honmou O, Kocsis JD (2009) BDNF-hypersecreting human mesenchymal stem cells promote functional recovery, axonal sprouting, and protection of corticospinal neurons after spinal cord injury. J Neurosci 29:14932-14941.

Seif GI, Nomura H, Tator CH (2007) Retrograde axonal degeneration ("dieback") in the corticospinal tract after transection injury of the rat spinal cord: a confocal microscopy study. J Neurotrauma 24:1513-1528.

Silver J, Miller JH (2004) Regeneration beyond the glial scar. Nat Rev Neurosci 5:146-156.

Tator CH. (2006) Review of treatment trials in human spinal cord injury: issues, difficulties, and recommendations. Neurosurgery 59:957-982, discussion 982-987.

Thau-Zuchman O, Shohami E, Alexandrovich AG, Leker RR (2010) Vascular endothelial growth factor increases neurogenesis after traumatic brain injury. J Cereb Blood Flow Metab 30:1008-1016.

Ting AE, Mays RW, Frey MR, Hof WV, Medicetty S, Deans R (2008) Therapeutic pathways of adult stem cell repair. Crit Rev Oncol Hematol 65:81-93.

Tom VJ, Steinmetz MP, Miller JH, Doller CM, Silver J (2004) Studies on the development and behavior of the dystrophic growth cone, the hallmark of regeneration failure, in an in vitro model of the glial scar and after spinal cord injury. J Neurosci 24:6531-6539.

Van't Hof W, Mal N, Huang Y, Zhang M, Popovic Z, Forudi F, Deans R, Penn MS (2007) Direct delivery of syngeneic and allogeneic large-scale expanded multipotent adult progenitor cells improves cardiac function after myocardial infarct. Cytotherapy 9:477-487.

Willis DE, Twiss JL (2006) The evolving roles of axonally synthesized proteins in regeneration. Curr Opin Neurobiol 16:111-118.

Yang Z, Suzuki R, Daniels SB, Brunquell CB, Sala CJ, Nishiyama A (2006) NG2 glial cells provide a favorable substrate for growing axons. J Neurosci 26:3829-3839.

Yasuhara T, Hara K, Maki M, Mays RW, Deans RJ, Hess DC, Carroll JE, Borlongan CV (2008) Intravenous grafts recapitulate the neurorestoration afforded by intracerebrally delivered multipotent adult progenitor cells in neonatal hypoxic-ischemic rats. J Cereb Blood Flow Metab 28:1804-1810.

Yin Y, Cui Q, Li Y, Irwin N, Fischer D, Harvey AR, Benowitz LI (2003) Macrophage-derived factors stimulate optic nerve regeneration. J Neurosci 23:2284-2293.

Yong VW (2005) Metalloproteinases: mediators of pathology and regeneration in the CNS. Nat Rev Neurosci 6:931-944.

Zhao LR, Duan WM, Reyes M, Keene CD, Verfaillie CM, Low WC (2002) Human bone marrow stem cells exhibit neural phenotypes and ameliorate neurological deficits after grafting into the ischemic brain of rats. Exp Neurol 174:11-20. 